\title{
« The time and the transitions back to work in France after maternity »
}

\author{
$\underline{\text { Auteurs }}$ \\ Bruno Rodrigues, Vincent Vergnat \\ Document de Travail $n^{\circ} 2018-14$
}

Mars 2018

Bureau d'Économie

Théorique et Appliquée

BETA Université de Strasbourg

Faculté des sciences économiques

et de gestion

61 avenue de la Forêt Noire

67085 Strasbourg Cedex

Tél. : +33 (0)368 852069

Fax : +33 (0)3 68852070

Secrétariat : Géraldine Del Fabbro g.delfabbro@unistra.fr 


\title{
The time and the transitions back to work in France after maternity
}

\author{
Bruno Rodrigues, Vincent Vergnat*
}

March 5, 2018

\begin{abstract}
Previous studies have shown that childrearing has a different impact on a mother's professional career, depending, among other reasons, on how much time passed from birth to returning to work. In this paper, we use a competing risks model to determine which variables may explain time out of work, as well as the transition back to work. In our study, mothers can decide to go back to the same employer, change employer and/or change labour supply. Our results show that it is mostly the age of the mothers at birth, their pre-birth wages, tenure, firm size, activity sector as well as the state of the economy as a whole that play a large role in the way young mothers go back to work, if at all.
\end{abstract}

Keywords: Maternity Leave, Labour Supply, Competing Risks

JEL classification: C14, D10, J13

*Rodrigues: STATEC Research, 13 rue Erasme, L-2013, Luxembourg and Bureau d'Économie Théorique et Appliquée (BETA), Université de Strasbourg, CNRS, 61 avenue de la Forêt Noire. Email: bruno.rodrigues@statec.etat.lu

Vergnat (corresponding author): Bureau d'Économie Théorique et Appliquée (BETA), Université de Strasbourg, CNRS, 61 avenue de la Forêt Noire. Email: vincent.vergnat@unistra.fr

The autors wish to thank Elena Stancanelli, Isabelle Terraz, Bertrand Koebel, Mathieu Lefebvre, François Legendre, François-Charles Wolff et Ralf Wilke for their helpful comments. The access to the data was carried through the CASD dedicated to researchers authorized by the French Comité du secret statistique. This work was supported by the CASD (Centre d'accès sécurisé aux données) and ANR FamPol project, grant ANR-10-EQPX-17 and ANR-14-FRAL0007 of the French Agence Nationale de la Recherche. Views and opinions expressed in this article are those of the authors and do not reflect those of STATEC, University of Strasbourg and funding partners. The authors gratefully acknowledge the support of the Observatoire de la Compétitivité, Ministère de l'Économie Luxembourgeoise, DG Compétitivité, Luxembourg, and STATEC 


\section{Introduction}

Eurostat figures for France in 2015 show that the employment rate of women between 20 and 49 years old without children is $76.4 \%$ and decreases to $70.9 \%$ for women with only one child (under 6 years old). The proportion of part time workers among women aged 20 to 49 without children is $20.4 \%$ and $24.9 \%$ for women with one child (under 6 years old). These figures show that women seem to change their labour supply after the birth of a child, but how?

Some studies show which transitions are done by young mothers (for example, Pailhé and Solaz, 2007 for France), however it would also be interesting to know more about which personal characteristics influence their decision to return, if at all, to work. Which types of women are more likely to come back to full time work? Does tenure in a firm play a role? Are past wages an important factor when deciding between going back to the previous employer or changing jobs? In other words, when and how are mothers coming back to work after giving birth? This paper attempts to answer these questions in the case of France, by estimating a competing risks model as in Arntz et al. (2017). Before continuing, it should be noted that henceforth, when we refer to post-natal leave, we mean the time out of work, from giving birth to going back to work. It is not the maternity leave in the legal sense. Of course this encompasses the legal maternity leave, which mothers are legally entitled to, but can also be longer, as some mothers may decide to stay at home until their child goes to school, for instance.

Similar questions have been addressed in the literature, focusing on different determinants than personal characteristics. For example, in Leibowitz et al. (1992), the authors study how the availability of childcare impacts the employment of mothers two years after giving birth to their first child. More recently, Geyer et al. (2015), shows that introducing universal childcare increases female labour supply by an average of 7 percentage points. Lalive and Zweimüller (2009) study the impact of two maternity leave reforms in Austria on future fertility decisions and on the career of mothers. The first reform, in 1990, was an extension of the job protection period, which, before the reform ended with the first birthday of the first child, and after the reform with the first birthday of the second child. The second reform, in 1996, was a six months reduction of the job protection period. The first reform increased fertility and return to work was delayed even after the job protection period had ended. The second reform shortened the pacing between the first and the second birth, but without major impact on total fertility. In a subsequent article, Lalive et al. (2014) study the impact of a third reform which was implemented in the year 2000. This reform increased the maximum duration of cash benefits the parents were entitled to for having a first child. This reform increased the time mothers spent at home before returning to work.

For France, Pailhé and Solaz (2007) studies the impact of a birth on the probability, for mothers, to invest less in the labour market. The authors show that the higher the birth order, the greater the likelihood of reducing working hours. Age at birth and education level also play an important role in the transitions made by mothers. Similarly, Domingo and Marc (2012), analyze the professional trajectories of mothers in France and in particular the effects of a break or a reduction of work. 
They show the importance of personal characteristics and the conditions of the last job on the occupational situation of the mothers after a birth. Davies and Pierre (2005); Meurs et al. (2010); Wilner (2016) are other papers that use French data but which mainly focus on the impact for mothers of childbirth on wages. Furthermore, Piketty (2005); Lequien (2012); Joseph et al. (2013), have studied the impact of parental leave reform on employment.

The papers from which we draw the most inspiration are Fitzenberger et al. (2016) and Arntz et al. (2017). Fitzenberger et al. (2016) use a dataset from a large German company to study the return to job of women after giving birth to a first child. Their data, covering the years from 2000 to 2008, show that return-to-job after a first birth is a source of high uncertainty for firms. Indeed, an important part of first mothers do not return to work after the parental leave. This is less the case for women who are more involved in their careers. This paper offers a very interesting and detailed analysis, however the conclusions are drawn from female workers of a single firm. Results from Fitzenberger et al. (2016) must thus be taken with some reservations. Arntz et al. (2017) use German data from 1985-2005, and focus on the link between labour market conditions, legislation, the length of maternity duration and the return to work. The authors show that there have been important changes in the behaviour of women during the last three decades. Women are more likely to give birth to a second child or to work again for the same employer, but part time, than getting back to work full time or dropping completely out of the labour market. It seems that the maternity leave legislation plays a role in this pattern. The authors show that the longer the job protection period, the longer the maternity leave taken by the mothers. This fact leads to important costs for the employer and for the economy as a whole. These findings might not be generalizable to France, however. Fertility and labour supply decisions of French women are quite different from their German counterparts. For example, total fertility rate is 1.47 in Germany while it is 2.01 for France in 2014. The percentage of part time working women aged 25 to 54 is $47.6 \%$ for Germany, against $28.7 \%$ for France in $2015 .^{1}$

Using a rich administrative dataset, we study young mothers' decisions; how long mothers decide to stay in post-natal leave, and how mothers come back. Different mothers, with different careers and working in different environments will take different decisions as to how long their break will be, and how they will come back to work. We use, as in Arntz et al. (2017), a competing risks model to study this question for France. After estimating the model, we discuss which variables affect how mothers return to work. The paper is constructed as follows: in section 2 we present France's institutional setting to give the reader a better understanding of the particularities of France, section 3 describes the data, section 4 the methodology employed, section 5 presents and comments the results. We conclude in section 6 .

\section{Institutional setting}

In France, since 1980, maternity leave is decomposed into two components: the prenatal leave (6 weeks for the first child) and the postnatal leave (10 weeks for the first

\footnotetext{
${ }^{1}$ Source: Eurostat.
} 
child). During this leave, mothers receive a compensation if they have contributed to a social security scheme some time before the leave and take a minimum of 8 weeks of maternity leave. The compensation is equal to the average income of the last three months before maternity leave with a daily ceiling of $84.90 €$ (in 2017). During maternity leave, a woman cannot be fired from her job. After the maternity leave, the employer has to give the mother her previous job or a similar job with at least the same wage. The maternity leave is considered as a period of effective service, thus the mother enjoys the same wage increase as employees of the firm with the same occupation. After the maternity leave, a mother (or father) can reduce her working hours to take care of her child until the child's third birthday. ${ }^{2}$ This leave can be paid or not paid.

Since 1990, the following parental leave provisions are available to parents of one child:

- Before 2004, only parents of at least two children were eligible for the parental leave provision.

- Since 2004, a new benefit was created, which now includes the parents of only one child, called Complément de Libre Choix d'Activité (CLCA). It allows parents of a child under three, who has contributed for 8 quarters to the public pension system in the last 2 years, to decrease their professional activity during six months. The amount of the benefits, per month, in January 2017, is $390.92 €$ if the parent stops working, $252.71 €$ for half-time work or less, and $145.78 €$ if the parent works for $50 \%$ to $80 \%$ of full time work. Before April 2014, depending on the household income, these amounts could have been increased by about $185 €$. The 6 months of paid parental leave can be divided between parents without any constraint.

- Since 2015, another benefit was introduced. The Prestation partagée d'écucation de l'enfant (PreParE) which, like the German Elterngeld, introduces an incentive for fathers to take a parental leave. The amounts and conditions, for parents of a first child, are the same as for the CLCA, but now, the paid parental leave lasts 1 year. Each parent can only take 6 months maximum. So to have access to the entire paid parental leave, both parents have to take a part.

Once the parents want to go back to work, many opportunities for childcare exist in France. Parents can also employ childminders. According to the DREES ${ }^{3}$, there are, on average in each department of metropolitan France, 68 places in preschool childcare facilities per 100 children under 3 years old in 2014. The French family allowance funds support some of the expenses related to childcare expenses (for parents who are working or searching for a job). Two major cases occur:

1. If the child goes to institutions hosting young children, such as nurseries:

- The price of childcare is computed based on the household's resources

\footnotetext{
${ }^{2}$ This is the so-called congé parental d'écucation in French.

${ }^{3}$ DRESS: Research Division of the French Ministry of Social Affairs and Health
} 
- Parents get a tax credit for their expenses for childcare.

2. If the child is cared for by a licensed childminder or by a childminder at the parent's home ${ }^{4}$ :

- In the case of the employment of a licensed childminder, parents are exempt of all social security contributions, and in the case of employment of a no-licensed childminder, of $50 \%$ of all social security contributions.

- More benefits to help parents finance the childminder (Allocation Garde d'Enfant à Domicile (AGED) and Aide à l'emploi d'une assitante maternelle agréée (AFEAMA) before 2004 and Complément de libre choix du Mode de Garde (CMG) afterwards).

- Tax credit for childcare expenses (after taking into account the potential benefits for childcare).

These different policies allow parents, especially mothers, to reconcile family and work life. Mothers are able to choose either to come back to their previous employer, or change employers, work full time or part time, or decide to have a long career break and take care of their child. These possibilities are of course also available to fathers, but for reasons that are not discussed in this paper, it is mostly mothers that are confronted to this choice. Our study focuses on the time a mother is not effectively working after giving birth, which encompasses the legal post-maternity leave and the potential parental leave.

\section{$3 \quad$ Data and descriptive statistics}

\subsection{The DADS-EDP panel}

The data used in this paper resulted from the merger of the DADS panel and the EDP dataset and is called "DADS-EDP". 5 The "DADS-EDP" panel covers the period from 1976 to 2010. These data are provided by the INSEE and give information on a sample of the French population. ${ }^{6}$ The sample is composed of persons born between the 1st and the 4th of October (only those born during an even year for the years 1967 to 2002 are included in the DADS-EDP panel). People born abroad, who never worked, who are self-employed or who work as civil servants of national public services are excluded from the data. Between 1967 and 2010, the sample evolved. Since 1991 and 1992, civil servants working in public institutions of an industrial and commercial nature are included in the panel as well as publiclyemployed hospital staff (since 1984) and civil servants of territorial communities (since 1988). Unemployment benefits recipients were also included in the panel

\footnotetext{
${ }^{4} \mathrm{~A}$ licensed childminder is a professional who cares for children at home, but unlike the nanny, is certified by the state.

${ }^{5}$ Déclaration Annuelle des Données Sociales or Annual Declaration of Social Data, Échantillon Démographique Permanent or Permanent Demographic Sample

${ }^{6}$ INSEE: National Institute of Statistics and Economic Studies. The French national statistical institute.
} 
in 2002 and agricultural workers in 2003. Residents of overseas territories were included in 2004. The merged "DADS-EDP" data provides information on sociodemographic variables such as date of birth, date of wedding, place of residence, level of education, number and date of birth of children... Data on wages, hours worked, type of employment contract, the starting and closing dates of the period of paid work are available for each individual and for each year of the panel. We also know the size, the employment sector and the location of the firm the person is working in. This merged dataset, provided as is, unfortunately does not contain every variable from either the DADS nor the EDP. For example, the EDP contains much more information on children for instance, such as whether the birth occurred at home or in a hospital, which is not available in the merged DADS-EDP.

Our variable of interest, duration of post-natal leave, is not available as such in the data, so we had to compute it. The raw data is in a spell format (one line for each job), so it is possible to compute the variable quite easily, for most cases. Here are the steps to create this variable:

1. The start date and the end date of paid work are observed, as well as the date of the birth of the child. We could therefore deduce the time that elapsed between the date of the birth of the child and the date of return to work.

2. In the data, some women never exit their jobs even if they give birth. These women might still be considered in the company's payroll software but left already, for example. For these women, we approximate the duration of postnatal leave using the reduction in hours worked between the civil year before the birth and the period around the birth (to do this we use the hours of work and the duration of pay variables). To control the results, or in the case of missing information on duration of pay, we divided the wage earned in the period around the birth by the hourly wage the year before to deduce the reduction of the working time during this period. ${ }^{7}$ We converted this reduction of working time around the birth that we convert into days and we subtracted 42 days (the legal duration of the pre-natal leave) as we are only interested in the duration of post-natal leave. ${ }^{8}$

3. Finally, there are some women for whom there are no exits from their job at the date of birth of the child (as in case 2) but for whom an exit of firm takes place before or during the end of the statutory maternity leave (70 days). For these women we computed the post-natal leave duration using the method described in point 2 (for the period surrounding the birth) to which we added the number of days during which the mother is not paid by a firm after the end of the legal post-maternity leave. ${ }^{9}$

\footnotetext{
${ }^{7}$ We suppose that hourly wages do not evolve between the civil year before birth and the year of the birth.

${ }^{8}$ The pre-natal leave may impact our approximation because the reduction of working time related to the birth can then begin the civil year before birth. So we have removed women who may have started prenatal leave the civil year before birth (women who gave birth to a child during the first 42 days of the year).

${ }^{9}$ Finally, for some women, there are no reductions in working hours or annual wages (mainly among civil servant) in the year of the child's birth. We decided to remove these women from the
} 
We also used information about the employer and the workload in the civil year before birth and year after birth to deduce the transitions made by the mothers. The four risks we consider a mother to be subject to are the following:

- A mother may return to the same employer, full time.

- A mother may return to the same employer, part time.

- A mother may return to another employer, full time.

- A mother may return to another employer, part time. ${ }^{10}$

There are mothers that never go back to working, but we cannot know the reason from the data. These observations are thus considered as censored. Some of these mothers may very well never return to work, ever, which in our context would constitute a defective risk. However, of these censored mothers, $88.3 \%$ had their child in 2010, the last year of observation, which suggests that most mothers end up going back to work again, and that censoring is thus orthogonal to mothers' characteristics, and thus, no bias in our estimations should be present. Also, one should keep in mind that our sample is constituted of mothers that were quite well integrated into the labour market, and that they have the right to return to their previous job if they so wish. We are thus fairly confident that there is not a defective risk present.

To explain women's decisions we considered a rich set of control variables; women's age, tenure and experience until the birth of their child, as well as their pre-birth wage. We divided the annual wage the year before birth into three classes (less than $20000 €$, between 20000 and $30000 €$ and more than $30000 €$ ). We added a dummy equal to 1 if the mother has already worked part-time in the past. Occupation is also included, again as a categorical variables divided into four levels: executives, intermediate occupations, clerks and blue-collar workers. The educational variable has a lot of missing values, so instead we chose to use the occupation categories as a proxy for education. We also added another categorical variable for the activity sector the mother worked in before giving birth, divided into four levels: industry, construction, trade and services.

Another variable that might influence women's decisions is the size of the firms where they worked before giving birth. We considered firms with less than 11 employees, with less than 50 but more than 10 and firms with more than 49 . We defined these three classes to take French legislation into account. Indeed, firms with more than 10 employees have to have staff representatives, and firms with more than 50 employees have to set up an employee representative committee. We further added a binary variable to take the policy change of parental leave of 2004 into account. This dummy equals 1 if the birth took place in 2004 or later, and 0 otherwise. We also added a dummy for eligibility to the CLCA (8 quarters of social contributions in the last two years). A marriage dummy is introduced in order

sample rather than assigning them the duration of the statutory maternity leave, as there is no way we could check this.

${ }^{10}$ We define part-time work using the variable $C E$ of DADS-EDP : 1: Full time and 2: Part time. 
to control for the family situation (we have access only to the information of the marriage, unmarried women living with a partner are not indicated). Finally, we created a variable measuring the distance between the city of work and the city of residence for each women, the year before birth. To do this, we used the geographical coordinates provided by INSEE for each municipality. This will allow us to test the hypothesis that women who have a long commute will be more inclined to reduce their labour supply or to change to an employer that might be closer to their place of residence. ${ }^{11}$

Macroeconomic variables included are the national GDP growth rate $^{12}$ and the unemployment rate at the French department level ${ }^{13}$ which control for the general state of the economy and the labour market. Unlike Arntz et al. (2017), we do not have information on the availability of childcare facilities at the local level. This might not be an issue in the specific case of France, since, as explained in the introduction, childcare facilities are very common in France, and a large number of benefits exist to help parents of any social class cover the costs.

\subsection{Descriptive statistics}

Our sample is restricted to women in metropolitan France who gave a first birth between 1995 and 2010 and who worked full time for at least 12 months at the same firm during the year before giving birth. The second condition makes it possible to have a relatively homogeneous pre-birth sample of women in terms of attachment to the labour market and only covers mothers who can access parental leave. We removed public servants because accounting for hours and wages does not allow for an adequate deduction of exit time from the labour market (see section 3.1). We suppressed observations where data the year before birth seemed to be wrong (hourly wages less than $6 €$ and annual hours less than 1600, as we focus only on women working full time the year before birth), which amounts to 1203 observations. We removed women for which data needed for the study were missing such as the activity sector, occupational categories or distance from home to work (128 observations). We further removed women who gave birth to a child during the 42 first days of a year (770 observations) because they may have started their maternity leave in the civil year preceding the birth. They may therefore have a reduction in earnings and hours worked in the civil year preceding the birth, which may impact the approximation of post-natal leave. Finally, we suppressed women who had a post-natal leave duration of 0 day (1060 women). We think that this situation can occur in companies that have implemented the full maintenance of the salary for mothers on maternity leave, preventing us from correctly approximating the post-natal leave because we do not observe a reduction in working time or salary the year of birth. ${ }^{14}$ The final sample

\footnotetext{
${ }^{11}$ The distance we computed is the great circle distance, and it might actually be a bad proxy or commuting time. Indeed, it is entirely possible to live close to one's working place and take very long to get there because of lack of public transportation or too much traffic. However, with this data, this is the best proxy we could come up with.

${ }^{12}$ Source: World Bank.

${ }^{13}$ Source: INSEE

${ }^{14}$ We did not find any particular characteristics associated with the wrong approximation of post-natal leave (post-natal leave of 0 day). This seems to be independent of the activity sector of
} 
is thus composed of 8467 women.

Table 1: Age at which women have their first child

\begin{tabular}{ccccccc}
\hline & Min & 1st quartile & Median & Mean & 3rd quartile & Max \\
\hline Age & 19.0 & 27.0 & 29.0 & 29.7 & 32.0 & 46.0 \\
\hline
\end{tabular}

Table 1 presents the age of mothers at the birth of their first child. The average age of childbearing is 29.7. In France, Volant (2017) shows that the average age varied over the period from 1989 to 2010 between 25.9 and 28 years and nearly $42 \%$ of the children born (in rank 1, 2 or 3) in 2010 have a mother aged between 27 to 32 . In our sample this number is $50 \%$. This difference can be explained by the presence in our sample of women who are relatively well integrated into the labour market. We have women who have been in full-time for at least 1 year in a same firm. These characteristics may not be relevant to younger mothers, which move our age distribution to the right.

Figure 1: Distribution of the duration of post-natal leave

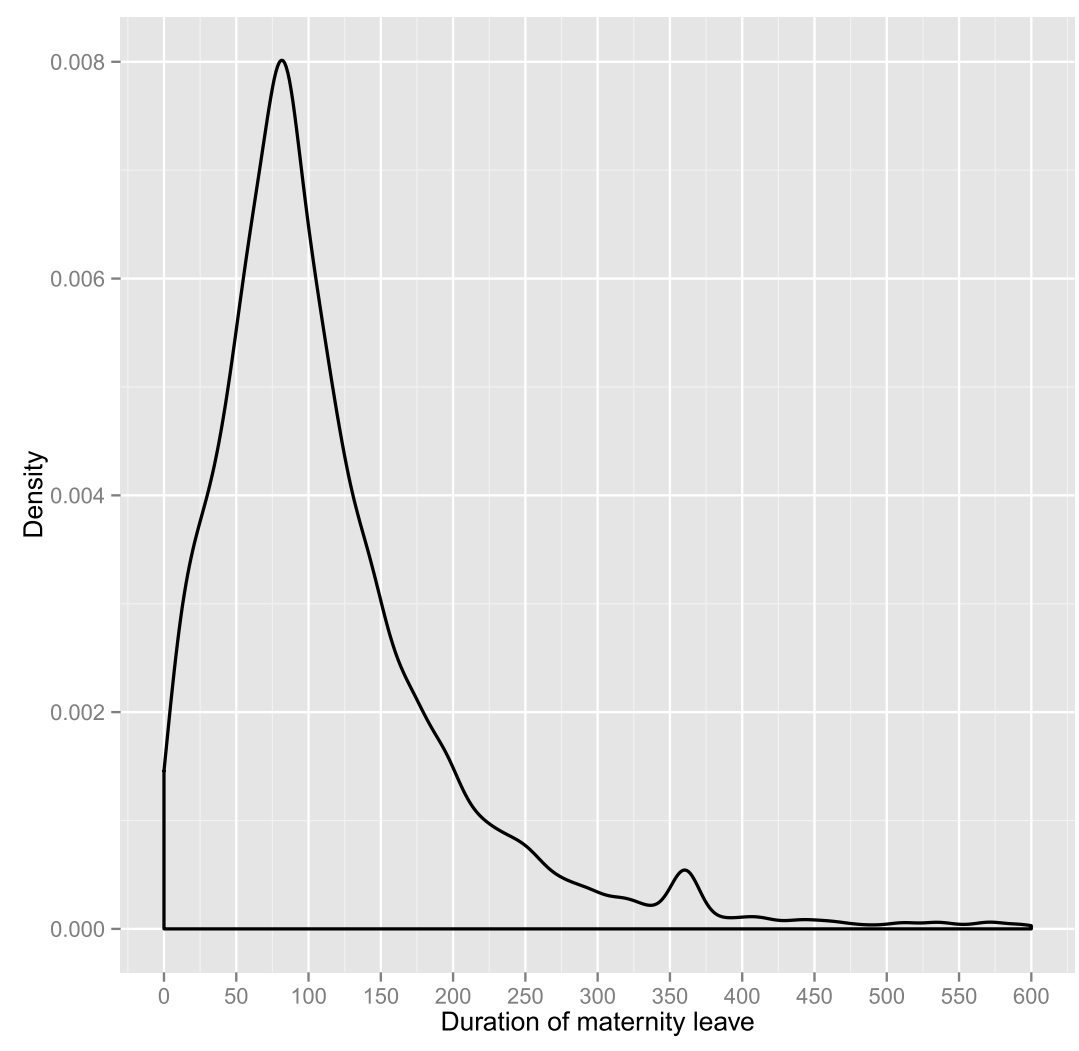

Figure 1 shows the distribution of the duration of the post-natal leave in the sample (without censored mothers), i.e. the number of days between the birth of

the firm or occupational categories. 
the child and the return to work. Our definition of post-natal leave therefore also includes possible parental leave. The distribution's mode is located around 85 days, which is slightly longer than the statutory duration of post-natal leave in France. There is also a small bump around the first birthday of the child. After the child's first birthday however, the number of women still in post-natal leave (in full time) decreases quickly.

Figure 2: Distribution of the duration of post-natal leave by transition

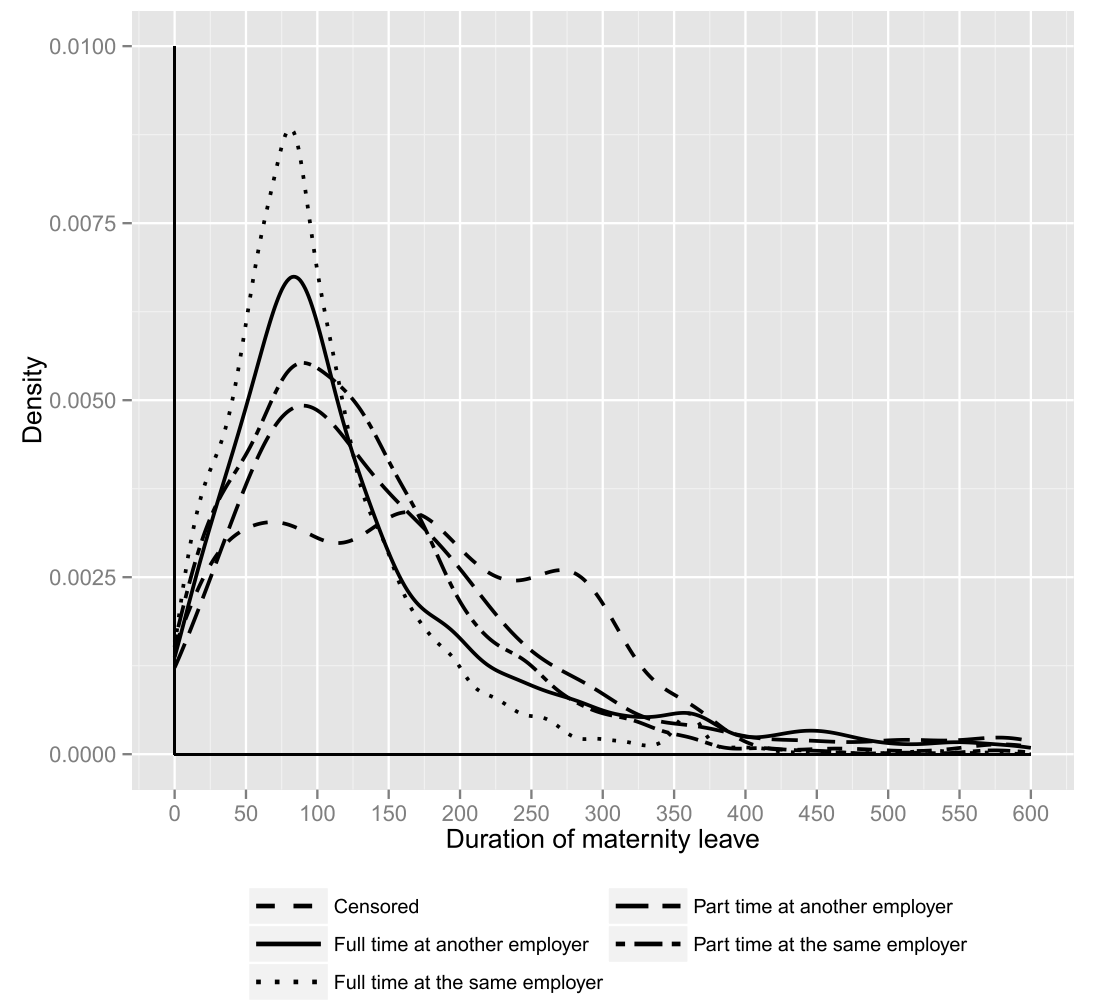

Table 2 shows some characteristics of the different transitions on which our study will focus (only for completed spells). The top row shows the proportion of mothers who transitioned to the different states. For instance, $57.8 \%$ of the women in the sample came back to full time work to their previous employer, while around $16 \%$ changed employers. Almost 17\% returned to part time work. In all, around $70 \%$ of young mothers returned to their previous employer. The total of the first row is not $100 \%$ because $13.1 \%$ of mothers in our sample are censored. What is striking is that post-natal leave duration, tenure and experience have very large standard deviations, which suggest very wide distributions for these variables, as shown in figure 2. However, it appears that the duration of post-natal leave is lower when women decide to return to the same employer. It is also these women who have more important professional experiences and tenure. Age of mothers is, for all risks, around 29-30. Mothers who come back to full time work at the same employer are those that have the highest average wage the year before the birth. The share of women living in the capital region ${ }^{15}$ is higher among women who change employers

${ }^{15}$ Ile de France 
Table 2: Mother's characteristics by observed transition

\begin{tabular}{|c|c|c|c|c|}
\hline & $\begin{array}{l}\text { Full time } \\
\text { same } \\
\text { employer }\end{array}$ & $\begin{array}{l}\text { Full time } \\
\text { another } \\
\text { employer }\end{array}$ & $\begin{array}{l}\text { Part time } \\
\text { same } \\
\text { employer }\end{array}$ & $\begin{array}{l}\text { Part time } \\
\text { another } \\
\text { employer }\end{array}$ \\
\hline Proportion & 57.8 & 11.7 & 13.3 & 4.1 \\
\hline Post-natal leave (in days) & $\begin{array}{r}106.9 \\
(95.8)\end{array}$ & $\begin{array}{l}166.6 \\
(198.8)\end{array}$ & $\begin{array}{l}132.0 \\
(112.3)\end{array}$ & $\begin{array}{l}225.1 \\
(322.1)\end{array}$ \\
\hline Age & $\begin{array}{r}29.7 \\
(4.0)\end{array}$ & $\begin{array}{r}29.0 \\
(3.9)\end{array}$ & $\begin{array}{r}30.6 \\
(4.3)\end{array}$ & $\begin{array}{r}29.4 \\
(4.3)\end{array}$ \\
\hline Tenure (days) & $\begin{array}{r}1155.4 \\
(811.4)\end{array}$ & $\begin{array}{l}976.7 \\
(730.3)\end{array}$ & $\begin{array}{r}1218.2 \\
(879.1)\end{array}$ & $\begin{array}{r}1030.9 \\
(770.6)\end{array}$ \\
\hline Experience (days) & $\begin{array}{c}2064.3 \\
(1209.9)\end{array}$ & $\begin{array}{c}1898.5 \\
(1162.1)\end{array}$ & $\begin{array}{r}2196.2 \\
(1322.2)\end{array}$ & $\begin{array}{l}1969.1 \\
(1286.4)\end{array}$ \\
\hline Annuel wage t-1 & $\begin{array}{r}20121.4 \\
(8411.7)\end{array}$ & $\begin{array}{r}19494.9 \\
(8158.2)\end{array}$ & $\begin{array}{r}19516.7 \\
(8037.9)\end{array}$ & $\begin{array}{r}17669.2 \\
(6026.7)\end{array}$ \\
\hline Part-time in the past(\%) & 59.7 & 61.2 & 61.8 & 61.1 \\
\hline Married (\%) & 39.7 & 40.0 & 36.7 & 39.1 \\
\hline Ile de France (\%) & 26.5 & 32.0 & 26.1 & 27.7 \\
\hline Post-reform CLCA & 60.1 & 53.4 & 59.4 & 44.7 \\
\hline \multicolumn{5}{|l|}{ Occupation. (\%) } \\
\hline Executive & 12.1 & 11.4 & 11.8 & 11.2 \\
\hline Intermediate occupation & 33.9 & 33.7 & 31.1 & 24.8 \\
\hline Clerk & 45.6 & 46.3 & 48.4 & 55.6 \\
\hline Blue collar worker & 8.4 & 8.6 & 8.8 & 8.4 \\
\hline \multicolumn{5}{|l|}{ Activity sector (\%) } \\
\hline Industry & 18.8 & 15.5 & 16.6 & 15.9 \\
\hline Construction & 1.7 & 1.6 & 1.7 & 2.0 \\
\hline Trade & 22.3 & 24.6 & 23.2 & 28.0 \\
\hline Service & 57.2 & 58.3 & 58.5 & 54.2 \\
\hline \multicolumn{5}{|l|}{ Firm size (\%) } \\
\hline$\leq 10$ employees & 17.6 & 22.3 & 17.4 & 27.4 \\
\hline$>11$ et $<50$ & 19.9 & 21.6 & 17.9 & 21.3 \\
\hline$\geq 50$ & 62.4 & 56.1 & 64.7 & 51.3 \\
\hline
\end{tabular}

For continuous variables, standard deviations are given between brackets. Firm variables concern the firm before birth. Tenure and experience are measured at the first day of the civil year of the birth. 
after birth, certainly reflecting a greater job mobility in this region. $60.1 \%$ of the mothers who come back to full time work to the same employer had their child in or after 2004 against $44.7 \%$ for those who return to part-time work at another employer. Since this reform, women seem to come back more often at the same employer. ${ }^{16}$ For each transitions, less than $10 \%$ of mothers are blue collar worker. The proportion of clerks is more important among mothers who come back to parttime work at another employer. Very few mothers work in the construction sector, but an important part of mothers work in services sector. The proportion of mothers working in services is less important among mothers who came back to part-time work at another employer. On the contrary, the proportion of mothers in the trade sector is higher. The share of mothers working in large firms is higher among women who came back at the same employer. Larger companies offer certainly more opportunities for mothers to take up their jobs on a part-time basis or to have more flexible hours of work. This might be much harder for smaller firms, which have less human resources at their disposal. The existence of employee representative committees or at least representatives of the staff may also foster more familyfriendly situations in larger companies.

\section{Econometric analysis 17}

A woman enters maternity leave for one reason only, but could then exit maternity leave in different ways. Young mothers are exposed to these risks during post-natal leave, so we are interested in the duration of the post-natal leave after the birth of their first child and on which variables influence the different risks. Because of data limitations, we do not know if a woman that never came back to work has moved out of the country, had a leave that ended after 2010 (the last year of observation) or died. It is also not possible to know if these mothers decided to have a second child during their first post-natal leave. These observations are thus considered as censored. From table 2, only $13.1 \%$ of observations are censored.

Typically, survival data is analyzed by first plotting the survival function. This is usually done with the non-parametric Kaplan Meier (KM) estimator. Then, researchers continue their analysis by estimating a Cox proportional hazards model, which links the hazard function to covariates. In the context of competing risks, one would define the Cox PH model as follows:

$$
\lambda^{r}(t, X)=\lambda_{0}^{r}(t) \exp \left(X_{i}^{T} \beta^{r}\right)
$$

where $\lambda_{0}^{r}$ is a cause-specific baseline hazard, and $\beta^{r}$ are cause specific covariates that are to be estimated. Let $r$ be one of the risks and $R$ the set of risk-set, such that $R \in \mathbb{R}$. Estimating (1) for, say, $r=1$, treats the other risks $r^{\prime} \neq 1$ as censored. However, considering the other risks as censored can lead to biased estimates if the risks are not independent. To overcome this shortcoming, we estimate a competing risks model based on the cumulative incidence curve (CIC). The CIC represents the

\footnotetext{
${ }^{16} 2004$ is a year were the CLCA was introduced, as explain in section 2 .

${ }^{17}$ The exposition here follows Kleinbaum and Klein (2005), as well as Fine and Gray (1999) and Arntz et al. (2017). We refer the interested reader to these texts for more details.
} 
probability of occurrence of risk $r$ before time $t$. In its simplest form, and in the absence of competing risks, the CIC is equal to $1-K M$. In the presence of competing risks, the CIC is obtained from the cause-specific hazard functions, such as (1). An assumption that is required by the CIC is that the overall hazard be the sum of the individual hazard for all risk types. This assumption is satisfied if the competing risks are mutually exclusive and if they can only occur once. Fine and Gray (1999) propose a model which links the impact of covariates on the cumulative incidence function via the subdistribution hazard. The subdistribution hazard represents the instantaneous probability for a mother to suffer the event $r$ in an infinitesimal small time interval, noted $\delta t$. The subdistribution hazard function for risk $r$ is defined as follows:

$$
\lambda_{s}^{r}(t, X)=\lim _{\delta t \rightarrow 0} \frac{\operatorname{Pr}\left(t \leq T^{r}<t+\delta t \mid T^{r}>t \text { or } T^{r^{\prime}} \leq t, r^{\prime} \neq r, X\right)}{\delta t}
$$

The conditioning in (2) means that no other event $r^{\prime}$ or no event at all have occured at time t. The subscript $s$ serves to distinguish this subdistribution hazard from (1).

The model developed by Fine and Gray (1999) is shown below:

$$
\lambda_{s}^{r}(t, X)=\lambda_{s, 0}^{r}(t) \exp \left(X_{i}^{T} \gamma^{r}\right)
$$

this model is very similar to (1). The difference comes from the fact that here the subdistribution hazard function $\lambda_{s}^{r}(t)$ is used instead the standard hazard function $\lambda^{r} . \gamma^{r}$ is the risk-specific vector of parameters to estimate.

To model the post-natal duration as well as the risks the mothers are exposed to, we estimate equation (3), using the $\mathrm{R}$ programming language. We use the finegray() as well as the coxph() functions from the survival package (Therneau, 2015b). We also used the cmprsk package (Gray, 2014), as Arntz et al. (2017) did, to check our results. To allow for individual heterogeneity we included an individual random effect in equation (3):

$$
\lambda_{s}^{r}(t, X)=\lambda_{s, 0}^{r}(t) \exp \left(X_{i}^{T} \gamma^{r}+u_{i}^{r}\right)
$$

Where $u_{i}^{r}$ is a random term derived from a Gaussian distribution, of mean zero, which is independently and identically distributed among individuals $i$. We used the coxme package (Therneau, 2015a) to estimate equation (4). Finally, we use the package crrSC (Zhou and Latouche, 2013) to estimate the model by clustering the observations by French departments and by activity sector. This accounts for the situation in which failure times may be correlated within a cluster. For instance, one could imagine that failure times in the Bas-Rhin, a French department culturally close to Germany, and with its own social security scheme are quite different from the failure times of a region in southern France. We also performed the analysis by activity sector clusters to take into account different branch agreements that may exist and that may impact the duration of the post-natal leave.

Before estimating these models, we present some graphs of the cumulative distribution function as well as the cumulative incidence function. Figure 3 show the Kaplan-Meier estimates of the cumulative distribution function (Kaplan and Meier, 
1958) for our risks. ${ }^{18}$ These graphs show the share of women who failed in one specific risk after a certain time has passed, but one has to remember that the competing risks are not taken into account and are simply considered as censored. The share of women who leave maternity to return to the same employer full time increase very rapidly unlike for the other transitions which happen much more slowly. There is also a much lower proportion of women who leave post-natal leave for part time work.

Figure 3: Kaplan-meier estimate of the cumulative distribution function for each risk

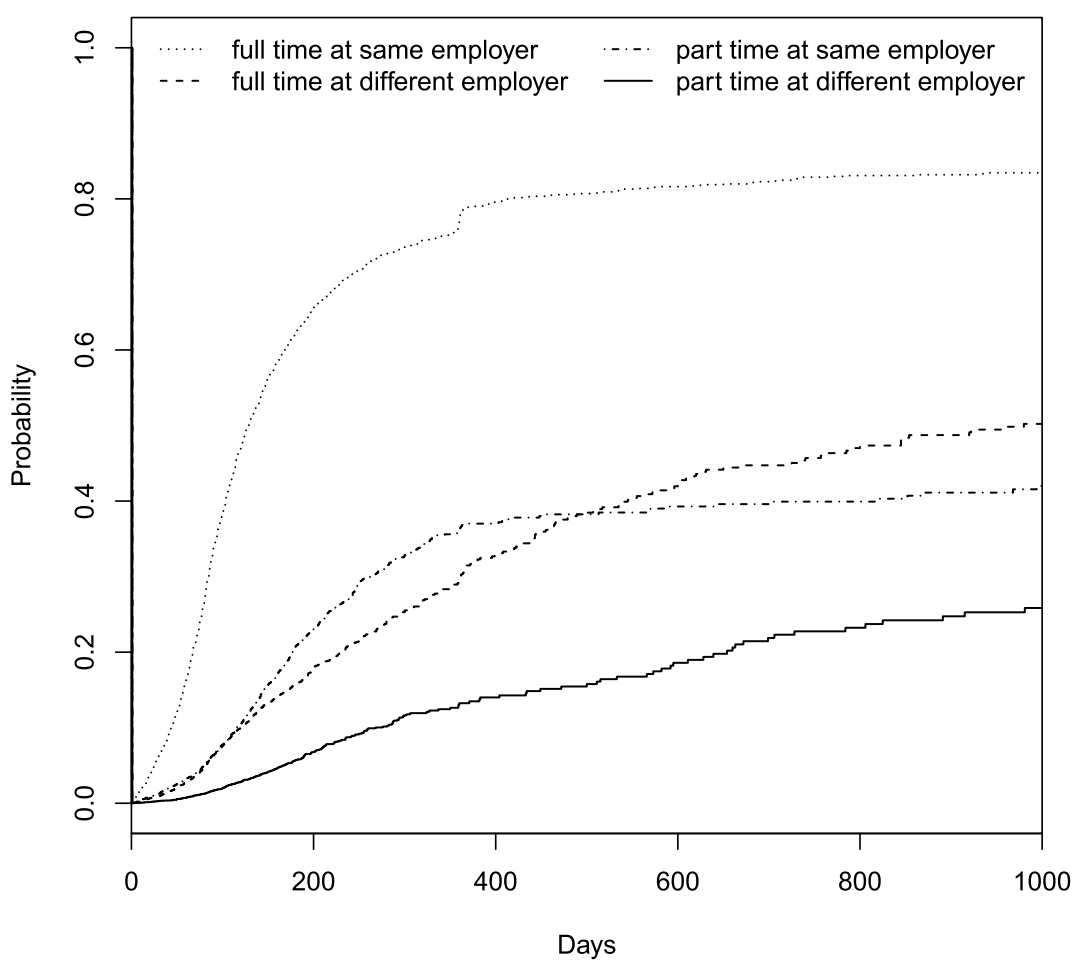

Figure 4 represents cumulative incidence functions without any covariates. In other words, it represents the probability to fail in one risk on or before time $t$ while taking into account the competing risks. The competing risks affect the probability of occurrence of an event. If we compare figure 4 with figure 3, we observe that the Kaplan-Meier estimates overestimated the probability of occurrence of each risk, which explains why it is important to take the presence of the other risks into account and why Fine and Gray (1999) use cumulative incidence functions in their model. We observe in figure 4 that the cumulative probability of occurrence of the risk "full time at same employer" is much more important than the 3 others risks. Each risk occurs relatively soon after birth except the risk "part time in a different employer" for which the cumulative incidence function grows much more slowly.

\footnotetext{
${ }^{18}$ The cumulative distribution function is the complement of the survival function.
} 
Figure 4: Cumulative incidence functions

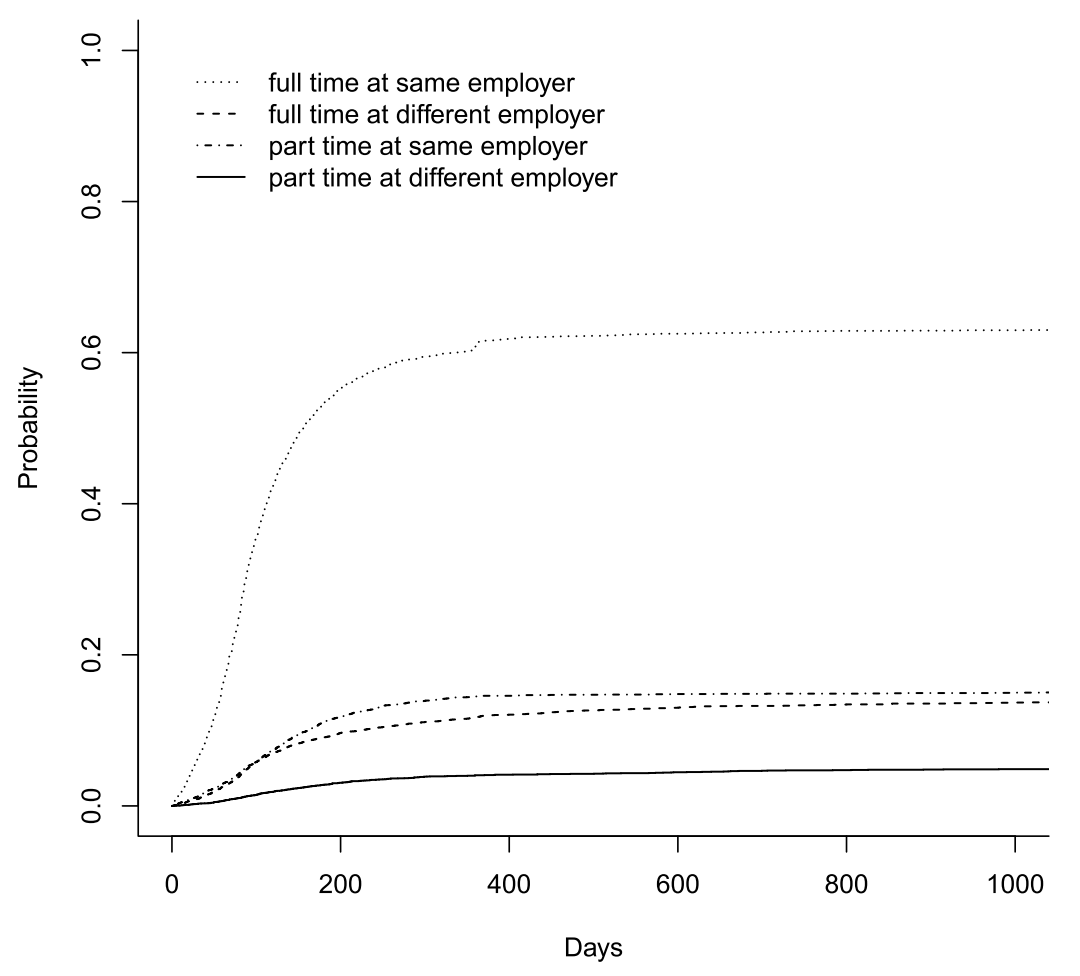

\section{Results and discussion}

Table 3 shows the estimation results of the competing risks regression (equation (3)) and table 4 shows the estimation of the competing risk model by clustering the observations by activity sector. We do not present the estimation results by clustering by French department and neither with unobserved heterogeneity because the results are very similar to those presented in table $3 .{ }^{19}$ Tenure and experience have been converted to years in order to have a similar scale between the variables. The reported coefficients are exponentiated, which allows us to present the results as risk ratios. This means that if a coefficient is greater than 1 , the variable increases the risk of occurrence of the event studied and will have the opposite effect if the coefficient is less than 1. For simplification purposes, we will refer to the subdistribution hazard by hazard. Let us first analyze the personal characteristics of the mother.

One year of added age decreases the hazard of both full time risks by around 2 to $4 \%$, while increasing the hazard by $6 \%$ to return to the same employer part time. Younger mothers tend to return more often to full time work, maybe because they want to limit the losses in their wages due to human capital depreciation, as well as signaling attachment to their previous company. Being married at the time of birth increases the risk of returning full-time to the same employer, perhaps reflecting a better division of labour between men and women in married couples that allows

\footnotetext{
${ }^{19}$ With unobserved heterogeneity, only the random coefficient for the risk "full time at the same employer" is significant and is equal to 0.397 . The tables are available upon request.
} 
Table 3: Fine and Gray competing risks regression results

\begin{tabular}{|c|c|c|c|c|}
\hline & $\begin{array}{l}\text { Full time } \\
\text { same } \\
\text { employer }\end{array}$ & $\begin{array}{l}\text { Full time } \\
\text { another } \\
\text { employer }\end{array}$ & $\begin{array}{l}\text { Part time } \\
\text { same } \\
\text { employer }\end{array}$ & $\begin{array}{l}\text { Part time } \\
\text { another } \\
\text { employer }\end{array}$ \\
\hline \multicolumn{5}{|l|}{ Personal characteristics } \\
\hline Age & $0,985^{* * *}$ & $0,963^{* * *}$ & $1,060^{* * *}$ & 1,002 \\
\hline Married & $1,070^{* *}$ & 1,000 & 0,969 & 0,904 \\
\hline Ile de France & $0,890^{* * *}$ & $1,302^{* * *}$ & 0,934 & 1,117 \\
\hline \multicolumn{5}{|l|}{ Professional characteristics } \\
\hline Tenure & $1,025^{* * *}$ & $0,911^{* * *}$ & 1,021 & $0,924^{* *}$ \\
\hline Experience & 0,996 & 0,997 & 0,986 & 1,002 \\
\hline Part time in the past & $0,878^{* * *}$ & 1,035 & 1,021 & 0,943 \\
\hline Distance work/home at t-1 & $0,999^{* * *}$ & $1,001^{* *}$ & 1,000 & $1,001^{*}$ \\
\hline \multicolumn{5}{|l|}{ Annual wage at $t-1$} \\
\hline Annual wage $<20 K$ & ref & ref & ref & ref \\
\hline Annual wage $\in[20 K, 30 K[$ & $1,084^{* *}$ & 1,057 & 0,944 & $0,762^{*}$ \\
\hline Annual wage $\geq 30 K$ & $1,367^{* * *}$ & 1,073 & $0,687^{* *}$ & $0,371^{* * *}$ \\
\hline \multicolumn{5}{|l|}{ Occupation } \\
\hline Executives & ref & ref & ref & ref \\
\hline Intermediate occupation & 1,089 & 1,105 & 0,898 & $0,532^{* * *}$ \\
\hline Clerk & 0,989 & 0,993 & 0,982 & 0,694 \\
\hline Blue collar worker & $0,825^{* *}$ & 1,195 & 1,027 & 0,635 \\
\hline \multicolumn{5}{|l|}{ Firm size at $t-1$} \\
\hline$\leq 10$ & ref & ref & ref & ref \\
\hline$\geq 11$ et $<50$ & $1,124^{* *}$ & 0,919 & 1,012 & $0,762^{*}$ \\
\hline$\geq 50$ & $1,183^{* * *}$ & $0,772^{* * *}$ & $1,236^{* *}$ & $0,645^{* * *}$ \\
\hline \multicolumn{5}{|l|}{ Activity sector at t-1 } \\
\hline Industry & ref & ref & ref & ref \\
\hline Construction & 0,909 & 1,057 & 1,222 & 1,179 \\
\hline Trade & $0,824^{* * *}$ & 1,197 & 1,145 & 1,192 \\
\hline Service & $0,872^{* * *}$ & 1,134 & 1,156 & 0,997 \\
\hline \multicolumn{5}{|l|}{ Parental leave legislation } \\
\hline Post-reform CLCA & 0,567 & 1,581 & 0,362 & 1,776 \\
\hline Eligibility at CLCA & 1,437 & $0,447^{*}$ & 2,437 & $0,378^{*}$ \\
\hline \multicolumn{5}{|l|}{ Economic environnement } \\
\hline GDP growth & $0,939^{* * *}$ & $1,059^{* * *}$ & 0,977 & $1,191^{* * *}$ \\
\hline Local unemployment rate & $0,969^{* * *}$ & 0,993 & 1,010 & 0,974 \\
\hline
\end{tabular}

Signifiance level : *** $\mathrm{p}<1 \%,{ }^{* *} \mathrm{p}<5 \%,{ }^{*} \mathrm{p}<10 \%(\mathrm{H} 0: \exp ($ coefficient $)=1)$ 
Table 4: Fine and Gray competing risks regression results with cluster by activity sector

\begin{tabular}{|c|c|c|c|c|}
\hline & $\begin{array}{l}\text { Full time } \\
\text { same } \\
\text { employer }\end{array}$ & $\begin{array}{l}\text { Full time } \\
\text { another } \\
\text { employer }\end{array}$ & $\begin{array}{l}\text { Part time } \\
\text { same } \\
\text { employer }\end{array}$ & $\begin{array}{l}\text { Part time } \\
\text { another } \\
\text { employer }\end{array}$ \\
\hline \multicolumn{5}{|l|}{ Personal characteristics } \\
\hline Age & $0,985^{* * *}$ & $0,963^{* * *}$ & 1,060 & 1,002 \\
\hline Married & $1,070^{* * *}$ & 1,000 & 0,969 & 0,904 \\
\hline Ile de France & $0,890^{* * *}$ & 1,302 & 0,934 & 1,117 \\
\hline \multicolumn{5}{|l|}{ Professional characteristics } \\
\hline Tenure & $1,025^{* * *}$ & $0,911^{* * *}$ & $1,021^{* * *}$ & $0,924^{*}$ \\
\hline Experience & $0,996^{*}$ & 0,997 & $0,986^{* * *}$ & 1,002 \\
\hline Part-time in the past & 0,878 & 1,035 & 1,021 & $0,943^{*}$ \\
\hline Distance work/home at t-1 & $0,999^{* * *}$ & $1,001^{* *}$ & 1,000 & $1,001^{*}$ \\
\hline \multicolumn{5}{|l|}{ Annual wage at $t-1$} \\
\hline Annual wage $<20 K$ & ref & ref & ref & ref \\
\hline Annual wage $\in[20 K, 30 K[$ & $1,084^{* * *}$ & 1,057 & 0,944 & $0,764^{* * *}$ \\
\hline Annual wage $\geq 30 K$ & 1,367 & 1,073 & $0,687^{* * *}$ & $0,371^{* * *}$ \\
\hline \multicolumn{5}{|l|}{ Occupation } \\
\hline Executives & ref & ref & ref & ref \\
\hline Intermediate occupation & $1,088^{* *}$ & 1,105 & 0,898 & $0,532^{* * *}$ \\
\hline Clerk & 0,989 & 0,993 & 0,982 & $0,694^{* *}$ \\
\hline Blue collar worker & $0,826^{* * *}$ & 1,195 & 1,027 & $0,635^{* *}$ \\
\hline \multicolumn{5}{|l|}{ Firm size at $t-1$} \\
\hline$\leq 10$ & ref & ref & ref & ref \\
\hline$\geq 11$ et $<50$ & $1,123^{* * *}$ & $0,919^{* *}$ & 1,012 & $0,762^{* * *}$ \\
\hline$\geq 50$ & 1,183 & $0,772^{* * *}$ & $1,236^{* *}$ & $0,645^{* * *}$ \\
\hline \multicolumn{5}{|l|}{ Activity sector t-1 } \\
\hline Industry & ref & ref & ref & ref \\
\hline Construction & $0,910^{* * *}$ & 1,057 & $1,222^{* * *}$ & $1,179^{* * *}$ \\
\hline Trade & 0,825 & $1,197^{* * *}$ & $1,144^{* * *}$ & $1,192^{* * *}$ \\
\hline Service & 0,872 & $1,134^{* * *}$ & $1,155^{* * *}$ & 0,997 \\
\hline \multicolumn{5}{|l|}{ Parental leave legislation } \\
\hline Post-reform CLCA & $0,568^{* * *}$ & $1,581^{* * *}$ & 0,362 & $1,776^{* *}$ \\
\hline Eligibility to CLCA & $1,436^{* * *}$ & $0,447^{* * *}$ & 2,436 & $0,378^{* * *}$ \\
\hline \multicolumn{5}{|l|}{ Economic environnement } \\
\hline GDP growth & 0,937 & $1,059^{* * *}$ & $0,977^{*}$ & $1,191^{* * *}$ \\
\hline Local unemployment rate & $0,969^{* * *}$ & 0,993 & 1,010 & $0,974^{* * *}$ \\
\hline
\end{tabular}


women to reconcile their work in full time and family life. This may also reflect the fact that the specialization of married couples takes place before the birth of a child. Thus, married women who have a child, have already decided at the time of marriage that they would invest in the labour market. On the contrary, married women who have decided to specialize more in domestic life may already do so before the birth of the child. These reasons may explain that being married increases the return at full-time work to the same employer. Living in the Île de France, the capital region, decreases the hazard of returning to the same employer by $11 \%$, while increasing the hazard of changing employer by $30 \%$. This clearly shows that mothers living in the capital region have much more job opportunities than in the rest of the country. However, once we cluster by activity sector, the hazard of changing employers is not significant anymore.

As for professional characteristics, tenure increases the hazard to return to the same employer by around 3\%, but decreases the hazard of changing employers by almost 10\%. Mothers that have been working in the same firm for a long time also tend to return to their previous employers, most probably as a way for these mothers to signal their attachment to their previous employer (or to avoid having to prove their worth again in a new firm), which is a result that is also found in Arntz et al. (2017) or Fitzenberger et al. (2016). They also have accumulated more firm specific human capital, and switching firms would cause that human capital to be, at least in part, wasted. Maybe surprisingly, overall job market experience does not play a role. This may be because we included age and tenure as further controls, which correlate highly with job market experience and may absorb the effect of tenure. Unsurprisingly, for mothers that worked part-time in the past, the hazard of returning full-time to the same employer decreases, perhaps reflecting a lower attachment of these women to the labour market. However, this variable has no effect on other transitions and its effect disappears when clustering by sector. The distance from home to work, while significant, has a very small effect. The probabilities of transition are very close to 0 , and this might come from the fact that distance as such does not matter, but rather, the time one takes to go to work. It would be very interesting to analyze the impact of this variable, on job transitions after giving birth, but another data source would be needed for that. One possibility would be to use a routing system such as $\mathrm{OSRM}^{20}$, but this is not possible via the secured system we have to use to access the data.

The pre-birth annual wage is the variable that has the largest effect. Compared to women in the reference category, the hazard of returning full time to the same employer for women earning between $20 \mathrm{~K}$ and $30 \mathrm{~K} €$ annually is $8 \%$ higher and around $25 \%$ lower to go work part-time for another employer. For women earning more than $30 \mathrm{~K} €$ annually, the hazard to return full-time to the same employer is $37 \%$ higher, and the hazard to go work part-time for the same employer or for another employer $31 \%$ and $63 \%$ lower respectively. Women who earned higher wages also tend to return to their previous employer in full time work. There is potentially a gift exchange game going on here; employers pay high wages to their female employees and thus these young mothers reciprocate by returning to work for them. The opportunity cost is also high for women with high wages (often, educated women) to

${ }^{20}$ http://project-osrm.org/ 
reduce their labour supply. Of course one would need to investigate this closely, by asking young mothers what is the primary reason they decided to go back to their previous employers, which is outside the scope of this current study. These effects seem robust, as clustering only changes the significativity of returning to the previous employer for women earning a high wage. The effect of wages on the speed of return to work for mothers had already been put forward by Leibowitz et al. (1992) or Arntz et al. (2017).

We used occupations and wages as proxies for education; as explained in section 3 the education variable was not of good quality and contained a lot of missing values. Being in an intermediate occupation decreases the hazard of switching to part-time work to another employer by $46 \%$ as compared to the reference category of executives, and also decreases the hazard of returning working full time for the same employer for blue collar workers by $17 \%$. When clustering, the estimated coefficients for the risk of changing employer and for part-time work for all occupations becomes significant.

Establishment size is another important predictor. As in Arntz et al. (2017), larger firms tend to have their employees return, either in full time or part time. The hazard of returning full time to the previous employer is $18 \%$ (which turns out to be non-significant when clustering) and $24 \%$ part-time. Switching employers for full-time work decreases the hazard by $22 \%$ and for part-time work by $35 \%$. A similar effect, albeit not so important in size can be seen for middle-sized firms. It could be easier for larger companies to offer part-time jobs. Indeed, in smaller firms, even if the law forces the employer, during the parental leave, to accept a request for parttime work, it is possible that pressure or organizational reasons prevent the mother from actually choosing her desired working hours. The presence of work councils, defending the rights of the staff, can also facilitate part-time returns. Domingo and Marc (2012) also showed that in France, the size of the firms matters for the return to employment of mothers.

The activity sector seems to play an important role. When looking at the estimation results clustered by activity sector, we see that the hazard ratio increases significantly for most risks, but not for returning full time at the same employer. Working in the trade or services decreases the hazard of returning to full time work to the same employer, by $18 \%$ and $13 \%$ respectively for the model without clustering. After controlling for clusters by sector of activity, for these 2 sectors, we note that the risk of returning to the same employer on a part-time basis or to work full time at another employer increases. In these sectors, the presence of industry-specific policies or agreements can influence the labour supply of mothers. More in-depth studies of different branch policies should be carried out to understand the effect of the industry on returning to work for mothers.

Eligibility for the CLCA becomes significant when clustering by activity sector; for mothers that are eligible to the CLCA, the hazard to return full-time to the same employer increases by $44 \%$. The reverse result is found for full-time at another employer. Eligibility for the CLCA seemed to have a real positive effect on employerretention for young mothers. This law can have incentivized employers to change attitudes about parental leave and offer more flexibility to mothers.

Macroeconomic variables, such as GDP growth and the unemployment rate (at 
the departmental level) were also included. GDP growth decreases the hazard of returning working full time at the same employer by $6 \%$ (but this effect disappears once we cluster by sectors), while increasing the hazard of changing employers (fulltime) by $6 \%$. It also increases the hazard of full-time work at another employer by $20 \%$. The local unemployment rate only decreases the hazard of returning working full-time at the same employer by $3 \%$, but also decreases the hazard of changing employers for part-time work. Unlike Arntz et al. (2017), we found that high unemployment rates decrease the hazard of returning full time to the previous employer, but we arrive at the same conclusion as Arntz et al. (2017) concerning GDP; higher GDP levels are associated with returns to part time work rather than full time work. Less uncertainty about the state of the economy can incite women to look for another job which can allow them to reconcile more easily family life and professional life. Conversely, poor economic conditions can lead to uncertainties in terms of sustainability of jobs and encourage mothers to return to their job quickly to prove their commitment to the company.

One of the limitations of our data is that it does not contain information on the activity or the income of the partner, if present. These elements can likely have an impact on the way women return to work, however, according to INSEE data, around $90 \%$ of one year old children live in a household with a couple (Chardon and Daguet, 2009). Also, for men aged 30-49, the employment rate is around $87 \%$ and only $4 \%$ of them work part time (Guedj, 2013). This means that women in our sample are most likely in a couple, with a partner that works full time, and assuming assortative mating, a phenomenon that exists for France, according to Frémeaux and Lefranc (2017), of similar education level and background as the mothers. This facts help mitigate the lack of information on the partner.

\section{Conclusion}

Women who end their post-natal leave (including parental leave) can make different transitions back to a job: returning to the same employer or changing employer and working on a part time or on a full time basis. Results from a competing risks model show that it is not the same women who perform each of these transitions. With this model, we show how individual, professional and legal variables affect the probability of occurrence of each transition. For instance, our model shows that women who worked in large firms tend to return to the same firms, but working part-time. This suggests that these larger firms have less problems to offer mothers the opportunity to work part-time. We have tested the effect of various other variables, however, these are variables upon which the policy maker does not have any influence. From our results, we see that the CLCA increased the probability for women to return to their previous employer. From the perspective of both the mother and the employer, this is beneficial, as it greatly reduces job-hunting as well as recruitment costs. The macroeconomic variables, which proxy for the state of the economy at large, also play a role into the decision process of young mothers. If we compare our result to the results of Arntz et al. (2017), we see that in both France and Germany, the post-birth transitions in the labour market seem to be influenced, in part, by the same variables. This does not mean, however, that the duration of post-natal leave 
and the proportion of consecutive births or mothers that work in part time are the same in both countries.

Results such as the ones we found might help individuals make choices that align better with their preferences, as well as help decision makers draft new policies.

Potential future research could focus on the effects of internal companies policies or branch agreements on how mothers return to employment. Understanding the different effects of these specific policies could help the state to find optimal policies for parents. Other sources of information could also be used such as survey data. This would be especially useful if these two sources, survey and administrative, could be merged. From the survey data, it would be possible to have information such as the health of the mother and of her children, commuting times, ability to choose working hours, etc. However, matching survey data with an administrative source can be very challenging, especially if a common identifying variable is missing. 


\section{References}

Arntz, M., Dlugosz, S., and Wilke, R. A. (2017). The sorting of female careers after first birth: A competing risks analysis of maternity leave duration. Oxford bulletin of economics and statistics, 79(5):689-716.

Chardon, O. and Daguet, F. (2009). Enfants des couples, enfants des familles monoparentales. des diffécerences marquées pour les jeunes enfants. Insee Première, (1216).

Davies, R. and Pierre, G. (2005). The family gap in pay in Europe: a cross-country study. Labour Economics, 12:469-486.

Domingo, P. and Marc, C. (2012). Trajectoires professionnelles des mères : Quels effets des arrêts et réductions d'activité? Politiques sociales et familiales, (108):8796.

Fine, J. P. and Gray, R. J. (1999). A proportional hazards model for the subdistribution of a competing risk. Journal of the American Statistical Association, 94(446):496-509.

Fitzenberger, B., Steffes, S., and Strittmatter, A. (2016). Return-to-job during and after parental leave. The International Journal of Human Resource Management, 27(8):803-831.

Frémeaux, N. and Lefranc, A. (2017). Assortative Mating and Earnings Inequality in France. IZA Discussion Papers 11084, Institute for the Study of Labor (IZA).

Geyer, J., Haan, P., and Wrohlich, K. (2015). The effects of family policy on maternal labor supply: Combining evidence from a structural model and a quasiexperimental approach. Labour Economics, 36:84 - 98.

Gray, B. (2014). cmprsk: Subdistribution Analysis of Competing Risks. R package version 2.2-7.

Guedj, H. (2013). Le taux d'emploi des hommes et des femmes. des écarts plus marqués en équivalent temps plein. Insee Première, (1462).

Joseph, O., Pailhé, A., Recotillet, I., and Solaz, A. (2013). The economic impact of taking short parental leave : Evaluation of a French reform. Labour Economics, 25:63-75.

Kaplan, E. L. and Meier, P. (1958). Nonparametric estimation from incomplete observations. Journal of the American statistical association, 53(282):457-481.

Kleinbaum, D. G. and Klein, M. (2005). Survival Analysis: A Self-Learning Text. Springer Science and Business Media, LLC.

Lalive, R., Schlosser, A., Steinhauer, A., and Zweimüller, J. (2014). Parental leave and mothers' careers: The relative importance of job protection and cash benefits. The Review of Economic Studies, 81(1):219-265. 
Lalive, R. and Zweimüller, J. (2009). How Does Parental Leave Affect Fertility and Return to Work? Evidence from Two Natural Experiments. The Quarterly Jounral of Economics, 124(3):1363-1402.

Leibowitz, A., Klerman, J. A., and Waite, L. J. (1992). Employment of new mothers and child care choice: Differences by children's age. The Journal of Human Resources, 27(1):112-133.

Lequien, L. (2012). The impact of parental leave duration on later wages. Annals of Economics and Statistics, pages 267-285.

Meurs, D., Pailhé, A., and Ponthieux, S. (2010). Child-related Career Interruptions and the Gender Wage Gap in France. Annals of Economics and Statistics, (100):15-46.

Pailhé, A. and Solaz, A. (2007). Inflexions des trajectoires professionnelles des hommes et des femmes après la naissance d'enfants. Recherches et prévisions, 90(1):5-16.

Piketty, T. (2005). Impact de l'allocation parentale d'éducation sur l'activité féminine et la fécondité en france. Histoires de familles, histoires familiales : les Cahiers de l'INED, (156):79-109.

Therneau, T. M. (2015a). coxme: Mixed Effects Cox Models. R package version 2.2-5.

Therneau, T. M. (2015b). A Package for Survival Analysis in S. version 2.38.

Volant, S. (2017). Un premier enfant à 28,5 ans en $2015: 4,5$ ans plus tard qu'en 1974. INSEE PREMIERE, (1642).

Wilner, L. (2016). Worker-firm matching and the parenthood pay gap : Evidence from linked employer-employee data. Journal of Population Economics, 29(4):991-1023.

Zhou, B. and Latouche, A. (2013). crrSC: Competing risks regression for Stratified and Clustered data. $\mathrm{R}$ package version 1.1. 